\title{
Negative Ion Formation of Pentaerythritol Tetranitrate in Atmospheric Pressure Chemical Ionization-Mass Spectrometry and in Corona Discharge Ionization-Ion Mobility Spectrometry
}

\author{
Sung-Seen Choi, ${ }^{*}$ Ok-Bae Kim, Yun-Ki Kim, Seung Geon An, ${ }^{\dagger}$ Myung-Won Shin, ${ }^{\dagger}$ Seug-Jin Maeng, ${ }^{\dagger}$ and Gyu Seop Choi ${ }^{\dagger}$ \\ Department of Chemistry, Sejong University, Seoul 143-747, Korea. *E-mail: sschoi@sejong.ac.kr \\ †'Wooju Communication \& Technology Co., Seoul 150-732, Korea \\ Received October 15, 2010, Accepted January 4, 2011
}

Key Words : APCI-MS, IMS, Pentaerythritol tetranitrate, Negative ion, Detection limit

Explosives have been divided into high and low explosives, the former used as detonating charges and the latter as propellants. Explosives have also been classified according to their chemical structures. Most organic explosives contain nitro groups and are subdivided into nitroaromatic compounds, nitrate esters, and nitroamines. ${ }^{1} 1,3,5-$ Trinitrobenzene (TNB), 2,4,6-trinitrotoluene (TNT), and 2,4-dinitrotoluene (DNT) belong to the nitroaromatic compounds, pentaerythritol tetranitrate (PETN) is one of the nitrate esters, and the nitroamines include 1,3,5-trinitro1,3,5-triazacyclohexane (RDX) and octahydro-1,3,5,7-tetranitro-1,3,5,7-tetrazocine (HMX). Explosives are unstable compounds and their polarities vary from moderate to high due to their nitro groups. These properties impose certain limitations on techniques used for their analysis, since explosives may decompose during analysis or result in poor chromatographic retention. Gas chromatography (GC) is suitable for the analysis of nitroaromatic compounds, but not for nitrate esters and nitroamines, which undergo thermal decomposition under the high temperature conditions of injector and oven. High-performance liquid chromatography (HPLC) would be a better alternative for the more unstable and polar explosives.

Common analytical techniques for the analysis of explosives include gas chromatography with electron capture detection, ${ }^{2}$ nitrogen phosphorus detection ${ }^{3}$ or mass spectrometry (MS), ${ }^{4}$ and HPLC with ultraviolet or MS detection. ${ }^{1,5-13}$ Recently, liquid chromatography/mass spectrometry (LC/ MS) with atmospheric pressure ionization (API) has been used for the analysis of explosives. ${ }^{1,10-13}$ Electrospray ionization (ESI) and atmospheric pressure chemical ionization (APCI) are the most currently used as API sources for LC/ MS. In APCI, a corona discharge generates reactant ions originated from solvent molecules in gas phase that are used to ionize the analyte by chemical ionization. ${ }^{15-19}$ Solvent and analyte are vaporized by pneumatic nebulization. APCI relies upon gas-phase ion-molecule reactions to place a charge on neutral analytes, so it is especially important to understand these reactions.

Ion mobility spectrometry (IMS) has been widely used to detect explosives, ${ }^{20-24}$ chemical warfare agents, ${ }^{25-28}$ and illegal drugs, ${ }^{15,23,28-30}$ and other trace compounds, ${ }^{31-33}$ since it combines both high sensitivity (detection limits down to ppb range) and relatively low technical expenditure with highspeed data acquisition. The time required to acquire a single spectrum is of several tens milliseconds. The working principle is based on the drift of ions at ambient pressure under the influence of an external electric field. ${ }^{34-40}$ IMS works in a similar way to a time-of-flight mass spectrometer (TOFMS). The major difference is that TOFMS requires a vacuum but IMS does not. The mean free path of ions in IMS is very smaller than in TOFMS. A typical IMS comprises of an ionization source associated with an ion reaction chamber, an ion drift tube, an ion/molecule injection shutter placed between the ion reaction chamber and the ion drift tube, and an ion collector (detector, typically Faraday plate). An ion swarm drifting under the electric field experiences a separation process based on ions with different masses or structures having different drift velocities. Collecting these ions on a Faraday plate delivers a time-dependent signal corresponding to the mobility of the arriving ions. This ion mobility spectrum contains information on the nature of the different trace compounds present in the sample gas.

Pentaerythritol tetranitrate (PETN) is a white and crystalline explosive used as a base charge in blasting caps and detonators, as the core explosive in detonating cord and in booster charges, and as a major ingredient in plastic explosives. ${ }^{9}$ Scheme 1 shows the chemical structure of PETN. In this study, we examined the negative ion formation of<smiles>O=[N+]([O-])OCC(CO[N+](=O)[O-])(CO[N+](=O)[O-])CO[N+](=O)[O-]</smiles>

Scheme 1. Chemical ctructure of PETN. 
PETN in APCI-MS and IMS. Dynamic ranges of detecting PETN in APCI-MS were investegated. Based on the analysis results of APCI-MS, the detection limit and reproducibility of PETN in the new IMS equipped with corona discharge ionization source in negative ion mode was examined. The sample was injected with liquid solution to the IMS to compare with the results of APCI-MS. An illustration of the basic ionization process of PETN in the IMS as well as in the APCI-MS was presented in Figure 1. For APCI-MS, the liquid sample evaporates through the nebulizing region and the vapors are ionized by corona discharge. The product ions are extracted to the capillary linked to the mass spectrometer. For the IMS, the sample solution of $1 \mathrm{~mL}$ was injected into the hole. The sample evaporated and flowed to the ionization chamber. Vapors of the solvent (acetonitrile) and PETN, air (nitrogen and oxygen), and water vapor exist in the ionization chamber. These gases are ionized by corona discharge and the product ions are formed by the ion-molecule reactions and charge transfer reactions. The product ions in the front of the shutter grid drift to the detector.

PETN was analyzed with APCI-MS. Both positive and negative modes were performed. In the positive ion mode, any product ion related PETN was not observed. In the negative ion mode, the APCI mass spectrum of PETN

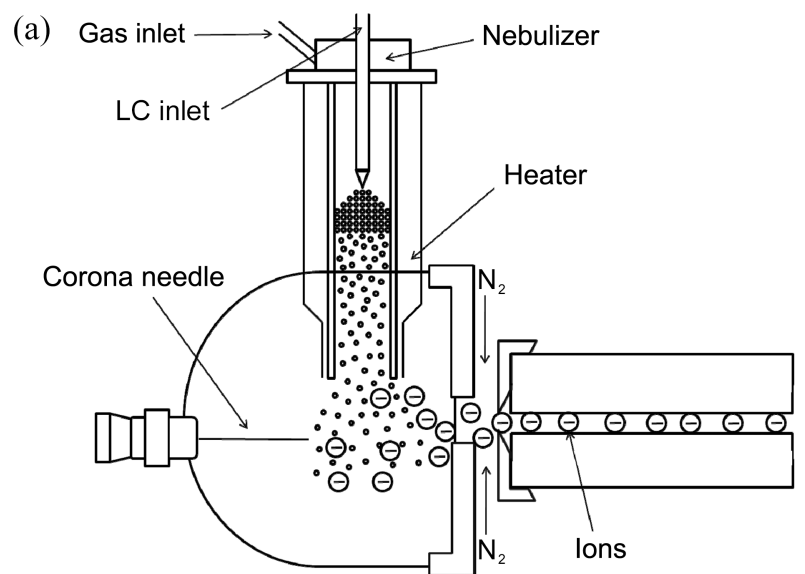

(b)

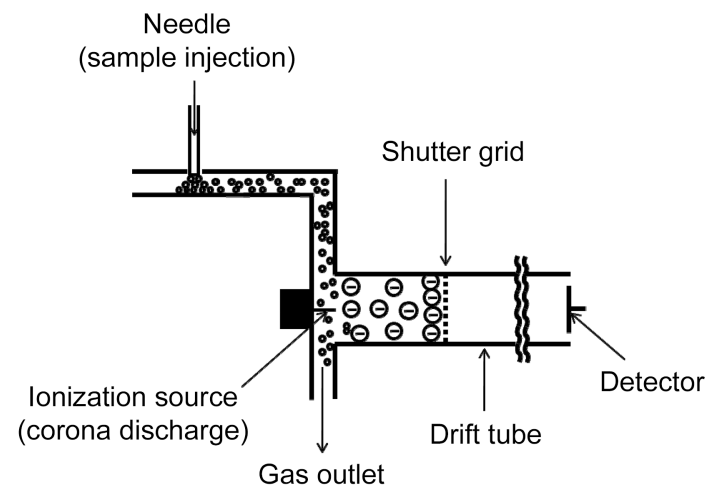

Figure 1. Schematic diagram of negative ionization process in atmospheric pressure chemical ionization-mass spectrometer (a) and in ion mobility spectrometer (b). displayed the $\mathrm{m} / \mathrm{z} 315,351,353$, and 378 which assigned to the $[\mathrm{M}-\mathrm{H}]^{-},\left[\mathrm{M}+{ }^{35} \mathrm{Cl}\right]^{-},\left[\mathrm{M}+{ }^{37} \mathrm{Cl}\right]^{-}$, and $\left[\mathrm{M}+\mathrm{NO}_{3}\right]^{-}$, respectively, as shown in Figure 2. The peak intensity ratios of $\left[\mathrm{M}+{ }^{35} \mathrm{Cl}\right]^{-}:\left[\mathrm{M}+{ }^{37} \mathrm{Cl}\right]^{-}$were 100:33. Tam and Hill analyzed explosives using IMS equipped with secondary electrospray ionization (SESI) and reported that [PETN+ $\mathrm{Cl}^{-}$was observed without any dopant such as methylene chloride. ${ }^{41}$ Asbury and coworkers analyzed RDX using ESIIMS and reported that $\left[\mathrm{RDX}+\mathrm{Cl}^{-}\right.$was observed without any chlorine dopant. ${ }^{42}$ They suggested that the chlorineadducted ion was mostly likely formed by ESI from trace impurities of the solvents. Besides trace impurities of the solvents as chlorine source, it can be considered that chlorine also comes from the air because there are residual chlorines (lower than $0.5 \mathrm{ppm}$ ) in tap water. Sources of atomic chlorine precursors are associated with tap water use, water and wastewater treatment, swimming pool disinfection, reactions of chlorides in sea salt aerosol, and use of biocides in cooling towers. ${ }^{43}$ In order to investigate the influence of chlorine dopant on the formation of [PETN+ $\mathrm{Cl}^{-}$, methylene chloride was employed as a chlorine dopant and mixture of PETN and methylene chloride was analyzed using APCI-MS. Methylene chloride of 0.1-1000 ppb were added to the $10 \mathrm{ppm}$ PETN solution, and variation of the relative ion intensity ratio of $[\mathrm{PETN}+\mathrm{Cl}]^{-} /[\mathrm{PETN}-\mathrm{H}]^{-}$with the concentration of methylene chloride was examined. The relative ion intensity ratios of $\left[\mathrm{PETN}+\mathrm{Cl}^{-} /[\mathrm{PETN}-\mathrm{H}]^{-}\right.$ were $3.56,3.75,3.72,3.00$ and 3.15 for the methylene chloride concentrations of $0.1,1,10,100$, and $1000 \mathrm{ppb}$, respectively. When no dopant was used, the $[\mathrm{PETN}+\mathrm{Cl}]^{-} /$ $[\mathrm{PETN}-\mathrm{H}]^{-}$ratio was 3.24. The relative ion intensity of $\left[\right.$ PETN $+\mathrm{Cl}^{-}$was notably enhanced by adding trace amount of methylene chloride $(\leq 10 \mathrm{ppb})$. Zhao and Yinon ${ }^{9}$ identified nitrate ester explosives including PETN by LC/MS and reported the $\left[\mathrm{PETN}+\mathrm{NO}_{3}\right]^{-}$was formed by adding $\mathrm{NH}_{4} \mathrm{NO}_{3}$ as an additive and the $[\mathrm{PETN}+\mathrm{Cl}]^{-}$was also generated by adding $\mathrm{NH}_{4} \mathrm{Cl}$ as an additive. Formation of $\left[\mathrm{PETN}+\mathrm{NO}_{3}\right]^{-}$was described in the literature. ${ }^{41}$

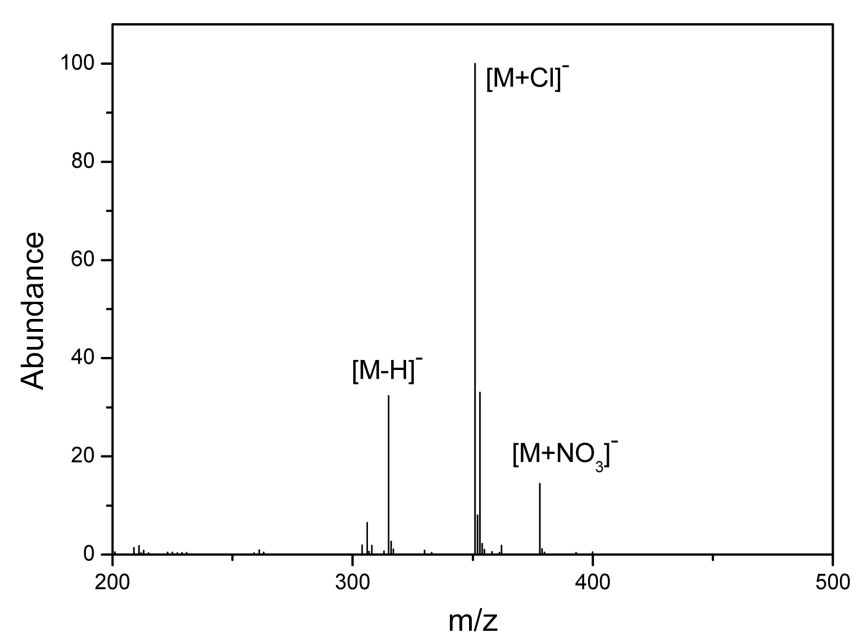

Figure 2. APCI-MS spectrum of 10 ppm PETN. Acetonitrile was used as solvent. 


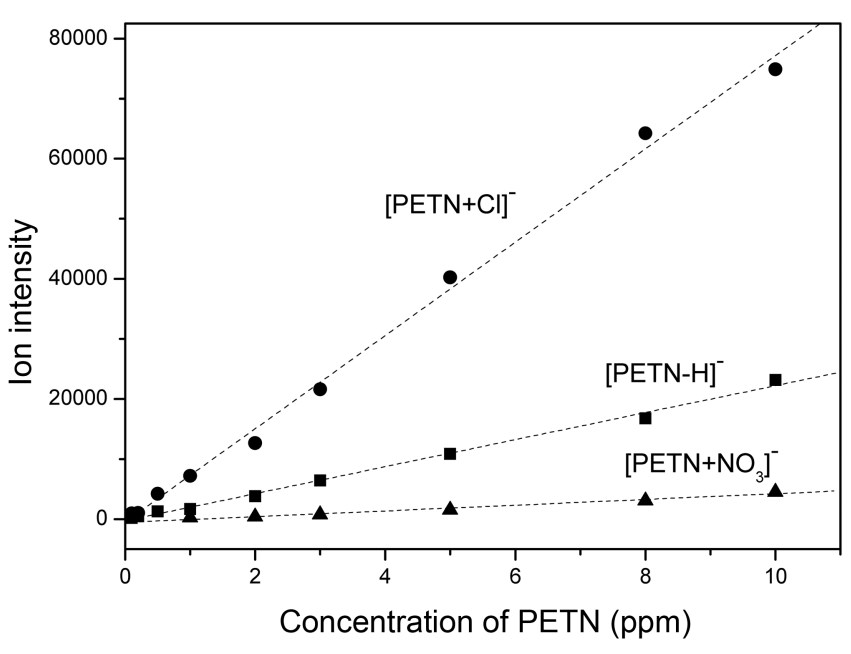

Figure 3. Calibration curves of the $\left[\mathrm{PETN}-\mathrm{H}^{-}\right.$(squares), $[\mathrm{PETN}$ $+\mathrm{Cl}]^{-}$(circles), and [PETN $\left.+\mathrm{NO}_{3}\right]^{-}$(triangles) detected in APCIMS.

In order to determine the dynamic range of PETN in APCI-MS, the ion intensities were observed as the concentration decreased. The detection limit of PETN in APCI-MS was below $100 \mathrm{ppb}$ in acetonitrile. The $100 \mathrm{ppb}$ PETN (the injection volume $10 \mu \mathrm{L}$ ) corresponds to $1 \mathrm{ng}$. Holmgren and coworkers ${ }^{1}$ reported that limit of detection (LOD) of the $[\text { PETN }+\mathrm{Cl}]^{-}$in LC/APCI-MS was $41.2 \mathrm{ng}$. Our results showed better LOD of the $\left[\right.$ PETN $+\mathrm{Cl}^{-}$than the results of Holmgren and coworkers. The calibration curves of the $[\mathrm{M}-\mathrm{H}]^{-},[\mathrm{M}+\mathrm{Cl}]^{-}$, and $\left[\mathrm{M}+\mathrm{NO}_{3}\right]^{-}$in the range of $0.1-10$ ppm were obtained as shown in Figure 3. The curve fitting equations were $\mathrm{y}=2249 \mathrm{x}-269(\mathrm{r}=0.998), \mathrm{y}=7761 \mathrm{x}-474$ $(\mathrm{r}=0.998)$, and $\mathrm{y}=478 \mathrm{x}-551(\mathrm{r}=0.989)$ for the [PETN $\mathrm{H}]^{-},[\mathrm{PETN}+\mathrm{Cl}]^{-}$, and $\left[\mathrm{PETN}+\mathrm{NO}_{3}\right]^{-}$, respectively. Sensitivity of the $\left[\mathrm{PETN}+\mathrm{Cl}^{-}\right.$was better than those of the $[\mathrm{PETN}-\mathrm{H}]^{-}$and $\left[\mathrm{PETN}+\mathrm{NO}_{3}\right]^{-}$by about 3.5 and 16 times, respectively. The experimental results indicate that analysis of PETN using APCI-MS had good detection limit and was good for quantitation.

For IMS analysis of PETN, the detection limit and reproducibility were examined. The injection volume was 1 $\mu \mathrm{L}$ and the analysis was performed five times at each concentration to check the reproducibility. Both positive and negative ion modes were performed. The product ions related to PETN were only generated in the negative ion mode (Figure 4). Besides the peaks of acetonitrile and reactive gases (air and water molecules), new peaks were observed in the IMS spectrum. The peaks at 44.7 and 47.5 ms were $[\mathrm{PETN}+\mathrm{Cl}]^{-}$and $\left[\mathrm{PETN}+\mathrm{NO}_{3}\right]^{-}$, respectively. The $[\mathrm{PETN}+\mathrm{Cl}]^{-}$and $\left[\mathrm{PETN}+\mathrm{NO}_{3}\right]^{-}$are principal product ions of PETN in IMS. ${ }^{41}$ The APCI results showed that the $\left[\mathrm{PETN}+\mathrm{NO}_{3}\right]^{-}$was less abundant than the $[\mathrm{PETN}+\mathrm{Cl}]^{-}$. However, in the IMS results, the peak intensity of [PETN + $\left.\mathrm{NO}_{3}\right]^{-}$was nearly the same to the $[\mathrm{PETN}+\mathrm{Cl}]^{-}$as shown in Figure 4.

The drift times $\left(t_{d} \mathrm{~s}\right)$ of $[\mathrm{PETN}+\mathrm{Cl}]^{-}$and $\left[\mathrm{PETN}+\mathrm{NO}_{3}\right]^{-}$ were $44.7 \pm 0.1$ and $47.5 \pm 0.3 \mathrm{~ms}$, respectively. Their

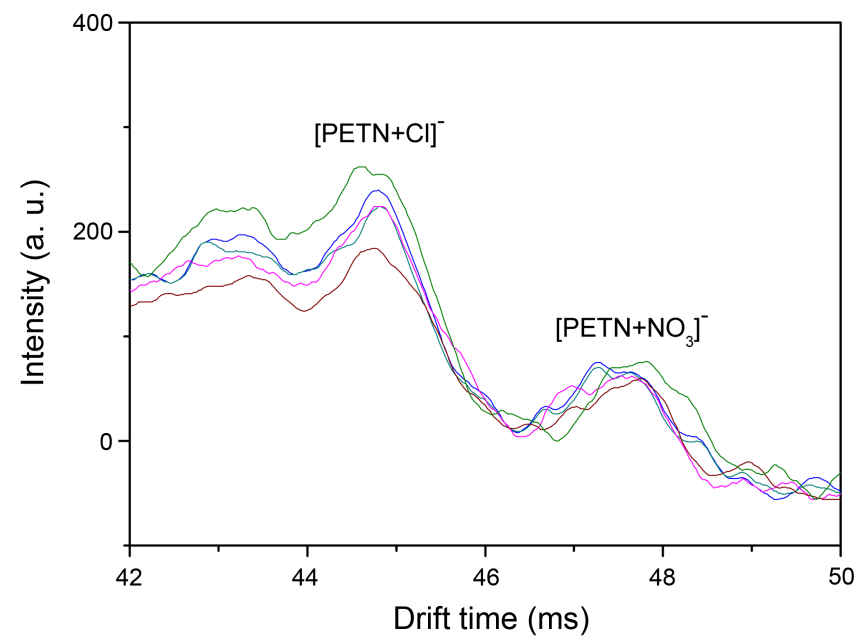

Figure 4. IMS spectra of $800 \mathrm{ppb}$ PETN.

relative standard deviations (RSDs) were less than $1.0 \%$. The detection limit of PETN in the IMS with corona discharge ionization was determined as the concentration decreased. The detection limit was $800 \mathrm{ppb}$. This corresponds to about $0.8 \mathrm{ng}$ (the injection volume was $1 \mu \mathrm{L}$ ). RSDs of the peak heights of [PETN $+\mathrm{Cl}]^{-}$and $[$PETN + $\left.\mathrm{NO}_{3}\right]^{-}$were 24 and $34 \%$, respectively. The ion mobility $(\mathrm{K}$, $\mathrm{cm}^{2} / \mathrm{V} \cdot \mathrm{sec}$ ) is defined by equations (1) and (2).

$$
\begin{gathered}
v_{d}=K \cdot E \\
K=v / E=L /\left(E \cdot t_{d}\right)
\end{gathered}
$$

where $v_{d}$ is the drift velocity of ion $(\mathrm{cm} / \mathrm{sec}), E$ is the electric field $(\mathrm{V} / \mathrm{cm}), L$ is the drift distance of ion $(\mathrm{cm})$, and $t_{d}$ is the drift time $(\mathrm{sec})$. The calculated $K s$ of $[\mathrm{PETN}+\mathrm{Cl}]^{-}$ and $\left[\mathrm{PETN}+\mathrm{NO}_{3}\right]^{-}$were $1.62 \pm 0.004$ and $1.52 \pm 0.009$ $\mathrm{cm}^{2} \cdot \mathrm{V}^{-1} \cdot \mathrm{s}^{-1}$, respectively, and their RSDs were 0.3 and $0.6 \%$, respectively. The drift time of ion in IMS is influenced by the pressure and temperature of the drift region. The reduced ion mobility $\left(K_{0}\right)$ is the pressure and temperature-corrected mobility. The reduced ion mobility is defined by equation (3).

$$
K_{0}=K[(P / 760) \times(273 / T)]
$$

where $T$ is the operating temperature $(K)$ of the instrument and $P$ is the current ambient pressure (torr). The calculated $K_{0}$ S of $\left[\mathrm{PETN}+\mathrm{Cl}^{-}\right]^{-}$and $\left[\mathrm{PETN}+\mathrm{NO}_{3}\right]^{-}$were $1.169 \pm 0.004$ and $1.101 \pm 0.006 \mathrm{~cm}^{2} \cdot \mathrm{V}^{-1} \cdot \mathrm{s}^{-1}$, respectively, and their RSDs were also 0.3 and $0.6 \%$, respectively. The previously reported $K_{0}$ value of $[\mathrm{PETN}+\mathrm{Cl}]^{-}$was $1.10 .^{44}$

From the experimental results, we can conclude that (1) the $[\mathrm{PETN}+\mathrm{Cl}]^{-}$and $\left[\mathrm{PETN}+\mathrm{NO}_{3}\right]^{-}$ions in APCI-MS were generated without any additives besides the [PETN $\mathrm{H}^{-}$, (2) the order of sensitivity of the major product ions in APCI-MS was $[\text { PETN }+\mathrm{Cl}]^{-}>[\text {PETN }-\mathrm{H}]^{-}>[$PETN + $\left.\mathrm{NO}_{3}\right]^{-}$, (3) the major product ions in IMS were $[\mathrm{PETN}+\mathrm{Cl}]^{-}$ and $\left[\mathrm{PETN}+\mathrm{NO}_{3}\right]^{-}$, and (4) the new IMS equipped with corona discharge ionization source had good detection limit of PETN and relatively good reproducibility. 


\section{Experimental Section}

PETN was obtained from the Korea army for analysis and acetonitrile was purchased from Aldrich Chemical Co. PETN was used by dissolving it with acetonitrile. LC/APCIMS of HPLC 1200 instrument coupled to a single quadrupole LC-MS 6130 mass spectrometer of Agilent Technologies Inc. was used as APCI-MS. The liquid chromatograph used a binary pump and an injection valve with a $10 \mu \mathrm{L}$ sample loop. A sample of $10 \mu \mathrm{L}$ was introduced by means of a Rheodyne valve. The eluent was the same solvent and the flow rate was $1.0 \mathrm{~mL} / \mathrm{min}$. MS detection was achieved using a single quadrupole spectrometer equipped with an APCI ionization source. The following instrumental parameters were used for the LC/APCI-MS analysis in the negative ion mode: capillary, $+4 \mathrm{kV}$; fragmentor voltage, $100 \mathrm{~V}$; corona current, $15 \mu \mathrm{A}$; quadrupole temperature, $100{ }^{\circ} \mathrm{C}$; vaporizer temperature, $325{ }^{\circ} \mathrm{C}$. Negative ionization process in APCIMS was described in Figure 1.

IMS equipped with corona discharge ionization source, Ionab IMS of Wooju Communication \& Technology Co. (Korea), was used. The analysis conditions of IMS were as follows: temperature of the sampling region was $200{ }^{\circ} \mathrm{C}$, temperatures of the ionization chamber and drift tube were $100{ }^{\circ} \mathrm{C}$, pressure in the drift tube was 750 torr, the electric field was $154.7 \mathrm{~V} / \mathrm{cm}$, and the drift distance of ion was 11.2 $\mathrm{cm}$. The $1 \mu \mathrm{L}$ sample was injected. The IMS analyses were performed five times at each concentration. Negative ionization process in IMS was also described in Figure 1.

Acknowledgments. This research has been supported by R\&BD Program (grant no. RBD-0901-0901-06-1) of Ministry of Knowledge Economy, Korea.

\section{References and Notes}

1. Holmgren, E.; Carlsson, H.; Goede, P.; Crescenzi, C. J. Chromatogr. A 2005, 1099, 127.

2. Jenkins, T. F.; Leggett, D. C.; Miyares, P. H.; Walsh, M. E.; Ranney, T. A.; Cragin, J. H.; George, V. Talanta 2001, 54, 501.

3. Batlle, R.; Carlsson, H.; Tollback, P.; Colmsjo, A.; Crescenzi, C. Anal. Chem. 2003, 75, 3137.

4. Sigman, M. E.; Ma, C.; Ilgner, R. H. Anal. Chem. 2001, 73, 792.

5. Gates, P. M.; Furlong, E. T.; Dorsey, T. F.; Burkhardt, M. R. Trends Anal. Chem. 1996, 15, 319.

6. Schreiber, A.; Efer, J.; Engewald, W. J. Chromatogr. A 2000, 869, 411.

7. Zhao, X.; Yinon, J. J. Chromatogr. A 2002, 946, 125.

8. Batlle, R.; Carlsson, H.; Holmgren, E.; Colmsjo, A.; Crescenzi, C. J. Chromatogr. A 2002, 963, 73.

9. Zhao, X.; Yinon, J. J. Chromatogr. A 2002, 977, 59.

10. Sanchez, C.; Carlsson, H.; Colmsjo, A.; Crescenzi, C.; Batlle, R.
Anal. Chem. 2003, 75, 4639.

11. Gapeev, A.; Sigman, M.; Yinon, J. Rapid Commun. Mass Spectrom. 2003, 17, 943 .

12. Schmidt, A.-C.; Niehus, B.; Matysik, F.-M.; Engewald, W. Chromatographia 2006, 63, 1.

13. Vigneau, O.; Machuron-Mandard, X. Talanta 2009, 77, 1609.

14. Buttner, W. J.; Findlay, M.; Vickers, W.; Davis, W. M.; Cespedes, E. R.; Cooper, S.; Adams, J. W. Anal. Chim. Acta 1997, 341, 63.

15. Choi, S.-S.; Kim, Y.-K.; Kim, O.-B.; An, S. G.; Shin, M.-W.; Maeng, S.-J.; Choi, G. S. Bull. Kor. Chem. Soc. 2010, 31, 2383.

16. Choi, S.-S.; Song, M. J. Rapid Commun. Mass Spectrom. 2008, $22,2580$.

17. Choi, S.-S.; Song, M. J. Bull. Kor. Chem. Soc. 2008, 29, 1847.

18. Choi, S.-S.; Kim, J.-C. Carbohydr. Res. 2010, 345, 408.

19. Choi, S.-S.; Kim, J.-C. Rapid Commun. Mass Spectrom. 2009, 23 , 3969.

20. Daum, K. A.; Atkinson, D. A.; Ewing, R. G. Int. J. Mass Spectrom. 2002, 214, 257.

21. Ewing, R. G.; Atkinson, D. A.; Eiceman, G. A.; Ewing, G. J. Talanta 2001, 54, 515.

22. Matz, L. M.; Tornatore, P. S.; Hill, H. H., Jr. Talanta 2001, 54, 171 .

23. Kanu, A. B.; Hill, H. H., Jr. Talanta 2007, 73, 692.

24. Guerra, P.; Lai, H.; Almirall, J. R. J. Sep. Sci. 2008, 31, 2891.

25. Kolakowski, B. M.; D’Agostino, P. A.; Chenier, C.; Mester, Z. Anal. Chem. 2007, 79, 8257.

26. Zimmermann, S.; Barth, S.; Baether, W. K. M.; Ringer, J. Anal. Chem. 2008, 80, 6671.

27. Rearden, P.; Harrington, P. B. Anal. Chim. Acta 2005, 545, 13.

28. Lai, H.; Corbin, I.; Almirall, J. R. Anal. Bioanal. Chem. 2008, 392, 105.

29. Ochoa, M. L.; Harrington, P. B. Anal. Chem. 2004, 76, 985.

30. Buryakov, I. A.; Baldin, M. N. J. Anal. Chem. 2008, 63, 787.

31. Baumbach, J. I. Anal. Bioanal. Chem. 2006, 384, 1059.

32. Mendes, M. A.; Pimpim, R. S.; Kotiaho, T.; Eberlin, M. N. Anal. Chem. 1996, 68, 3502.

33. Eiceman, G. A. Trends Anal. Chem. 2002, 21, 259.

34. Guo, Y.; Wang, J.; Javahery, G.; Thomson, B. A.; Michael Siu, K. W. Anal. Chem. 2005, 77, 266.

35. Shvartsburg, A. A.; Li, F.; Tang, K.; Smith, R. D. Anal. Chem. 2006, 78, 3706 .

36. Kanu, A. B.; Gribb, M. M.; Hill, H. H., Jr. Anal. Chem. 2008, 80, 6610.

37. Young, D.; Eiceman, G. A.; Breach, J.; Brittain, A. H.; Thomas, C. L. P. Anal. Chim. Acta 2002, 463, 143.

38. Gillig, K. J.; Ruotolo, B. T.; Stone, E. G.; Russell, D. H. Int. J. Mass Spectrom. 2004, 239, 43.

39. Purves, R. W.; Guevremont, R.; Day, S.; Pipich, C.; Matyjaszczyk, M. S. Rev. Sci. Instrum. 1998, 69, 4094.

40. Lia, F.; Xiea, Z.; Schmidta, H.; Sielemannb, S.; Baumbach, J. I. Spectrochim. Acta B 2002, 57, 1563.

41. Tam, M.; Hill, H. H., Jr. Anal. Chem. 2004, 76, 2741.

42. Asbury, G. R.; Klasmeier, J.; Hill, Jr. H. H. Talanta 2000, 50, 1291.

43. Chang, S.; McDonald-Buller, E.; Kimura, Y.; Yarwood, G.; Neece, J.; Russell, M.; Tanaka, P.; Allen, D. Atm. Environ. 2002, 36, 4991.

44. Eiceman, G. A.; Karpas, Z. Ion Mobility Spectrometry, 2nd ed.; CRC Press: New York, 2005; p 260. 